DOI: 10.12957/demetra.2015.15438

\title{
Relações socioculturais em torno da alimentação do paulistano como formação de uma identidade cultural e construção da nação brasileira
}

\section{Socio-cultural relations in feeding of people living in sao paulo in the formation of cultural identity and construction of the brazilian nation}

Talita Prado Barbosa Roim?

1 Universidade Estadual Paulista "Júlio de Mesquita Filho", Faculdade de Filososofia e Ciências de Marília. Marília-SP, Brasil.

A primeira versão deste texto foi apresentada na 29ª Reunião Brasileira de Antropologia, realizada entre os dias 03 e 06 de agosto de 2014, Natal-RN.

Correspondência / Correspondence Talita Prado Barbosa Roim

E-mail: talitaprado.sociais@yahoo.com.br

\section{Resumo}

Com o objetivo de compreender as relações socioculturais entre indivíduos que compõem o cenário do Mercado Municipal de São Paulo - vendedores, consumidores e turistas -, pretende-se construir um paralelo imaginário da cidade de São Paulo como lugar reconhecidamente cosmopolita. A partir da observação do cotidiano desses personagens, percebe-se que o Mercado Municipal atua não mais como mercado distribuidor de alimentos, mas como centro turístico que oferece produtos nacionais e internacionais, além de guloseimas que foram selecionadas como ícones da cidade de São Paulo. O mercado Municipal Paulista, ponto turístico demarcado pela tradição que representa a diversidade da cidade, possui comerciantes de diferentes etnias vendendo produtos genuínos de suas terras que, em certa medida, contribuíram para compor o paladar e o prato do paulistano, o que se entende tratar de uma tradição inventada no sentido de Eric Hobsbawm. A pesquisa de cunho antropológico contempla a reflexão da construção do Brasil como nação a partir de uma classificação da culinária paulista representada pelo comércio do Mercado Municipal que agrega alimentos locais, regionais, nacionais e globais, dimensões estas que permitem pensar o Brasil como nação, e a cidade como possível capital do mundo. Acredita-se que o Mercado Municipal seja um espaço propício para construir reflexões acerca das transformações das relações sociais estabelecidas no contexto da contemporaneidade dos paulistanos e, enfim, de elementos que compõem uma cultura identitária e do processo civilizador do Brasil como nação e de São Paulo como seu representante.

Palavras-chave: Antropologia. Brasil. Características Culturais. Interação Social. Hábitos Alimentares. Pesquisa Qualitativa. 


\section{Abstract}

In order to understand the socio-cultural relations among individuals that make up much of the Municipal Market of Sao Paulo - sellers, consumers and tourists - we intended to build an imaginary parallel of the city of Sao Paulo, known as a cosmopolitan place. From the observation of the daily lives of these characters, it is clear that the Municipal Market operates not as a food market distributor, but as a tourist center that offers domestic and international food, as well as goodies that were selected as icons of the city of São Paulo. São Paulo's municipal market, tourist spot marked by tradition representing the diversity of the city, has traders of different ethnicities selling genuine products from their lands, which to some extent contributed to make up the taste of Sao Paulo, which is meant to be an invented tradition according to Eric Hobsbawm. The anthropological research includes reflections on the construction of Brazil as a nation, based on Sao Paulo cooking classification represented by the Municipal Market trade that brings together local, regional, national and global food, dimensions that allow thinking of Brazil as a nation, and the city as a possible capital of the world. We believe that the Municipal Market is a propitious space to build reflections on the transformation of social relations in the contemporary context of Sao Paulo and, in short, elements that make up a cultural identity and the civilizing process in Brazil as a nation and Sao Paulo as its representative.

Key words: Brazil State. Interpersonal Relations. Food Habits. Cultural Characteristics. Anthropology. Qualitative Research.

\section{Introdução}

O principal objetivo deste texto foi construir arsenal teórico-metodológico para refletir sobre a produção de tradições para a formação de identidades e sentimentos de pertencimento em determinados grupos, incluindo a ideia de identidade nacional. São trabalhados conceitos e noções teóricas, especificamente com a proposta elisiana de processo civilizado. Para tanto, discutimos alguns termos-chave para compreender a formação de tradição, identidade e nação a partir de hábitos alimentares, tendo como pano de fundo as relações socioculturais observadas no Mercado Municipal de São Paulo.

A partir de uma visão sobre a construção identitária dos indivíduos como um processo, temos como objetivo debater as relações socioculturais das personagens que fazem parte da composição do espaço do Mercado Municipal de São Paulo. Partindo do conceito de fato social total de 
Marcel Mauss, ${ }^{1}$ é possível perceber a complexidade das relações estabelecidas nesse espaço que agrega comércio, alimentação, turismo, consumo, modernidade e tradição nas relações entre os comerciantes, vendedores, funcionários, clientes e turistas. Tomamos o Mercado Municipal Paulista como espaço que nos leva a pensar sobre as novas e velhas relações ali vivenciadas, tendo como base para a reflexão a alimentação, objeto que possibilita tais relações que vão de laços familiares a disputas de legitimidade e ocupação de um espaço dentro do estabelecimento.

Norbert Elias² aponta que gestos, vestuários, comportamento, expressões corporais, a escolha de alimentos e os modos à mesa são características de uma conduta própria de determinadas sociedades. Indicam como uma configuração de tais manifestações pode se disseminar nas sociedades, criando diferentes comportamentos que podem se encaminhar para um processo civilizador, construindo hábitos pertinentes ou não a determinados grupos sociais, formando identidades coletivas.

As transformações históricas, políticas e sociais levam a novos comportamentos, evidenciando o processo de formações identitárias - neste caso, buscamos informações particulares do cotidiano dos indivíduos que mantêm relações socioculturais e econômicas no Mercado Municipal, procurando ao mesmo tempo contextualizá-las em um movimento dinâmico e plural da sociedade, evidenciando manifestações que formam uma possível identidade paulistana.

Esta pesquisa tem como princípio observar os hábitos e comportamentos das personagens que fazem parte desse cenário, podendo indicar transformações em um processo de construção de identidades coletivas, como afirmação de uma autoimagem diferenciada. Permite, dessa maneira, realizar uma sociologia das relações que são construídas nos diferentes espaços, proporcionando uma análise do micro e do macro que atuam em um espaço específico - no caso, o Mercado Municipal de São Paulo. Entendemos que, ao observarmos as relações socioculturais do Mercado, iremos compreender alguns dos comportamentos de um grupo de indivíduos para, então, refletir sobre uma sociedade contemporânea e cosmopolita, como é a cidade de São Paulo.

As relações sociais nesse ambiente são determinadas pela posição ou status social em que cada indivíduo ocupa - vendedor e permissionário, cliente e turista - gerando um território de disputas, sejam por espaço, por concorrência, por fidelidade ou por tradição.

Elias $^{3}$ mostra que os conceitos de sociedade e de indivíduo podem ser partes de uma mesma realidade, na medida em que são fruto da sociedade contemporânea, entendida aqui como supermoderna, ${ }^{4}$ com a supervalorização da identidade-eu (do indivíduo como responsável pelo próprio destino), mas que em outros momentos tal valorização já foi pela oposição, a identidadenós (da coletividade, na noção de que a união faz a força). Tais construções perpassam interesses e posições que os indivíduos ocupam em determinados grupos. Cabe aqui entender quais são esses interesses e posições que ora optam pela valorização da individualidade, ora pela valorização da coletividade. 
Dessa maneira, partimos das categorias de "processo" e "configuração social" propostas por Norbert Elias, ${ }^{2}$ que propõe uma linha teórica que contemple todos os aspectos que envolvem a totalidade que constitui o ser humano, de forma a não a fragmentá-la.

O ambiente do Mercado Municipal torna-se propício a coexistências complexas, na medida em que podemos perceber diferentes interesses estabelecidos nessas relações. Partindo da ideia do autor, de que a singularidade do ser humano se estabelece na medida em que ele se reconhece como ser social, temos por percurso metodológico - observações em campo e entrevistas com permissionários e vendedores - o de alcançar as percepções individuais, a flexibilidade e dinamismo das relações mais particulares constituidoras de uma rede de interdependências.

Os espaços no Mercado são formados por essas redes de relações interdependentes, em que são observadas entre os diferentes indivíduos - como por exemplo, vendedores das bancas de frutas, vendedores dos empórios e vendedores das lanchonetes. Todos esses agentes formam um campo diferenciado, sendo que cada um oferece diferentes valores, relações de trabalho, etc., que são compreendidas de maneira diferentes.

O tratamento de clientes e turistas também é diferenciado; há nessa relação uma classificação identitária, que forma uma noção de quem é de dentro e quem é de fora - ou seja, quem é o cliente (na maioria das vezes classificado como o paulistano) e quem é o turista. Dessa maneira, certos costumes e hábitos são encarados de formas diferentes. Ocorre diferenciação de comportamentos de clientes e turistas, que têm, por essência, diferentes interesses pelo campo do Mercado. Enquanto os primeiros visam comprar suprimentos e produtos que fazem parte da sua alimentação diária, o segundo grupo tem interesse em apreciar o ambiente, conhecer o espaço e os produtos que ali são comercializados.

Essas múltiplas relações implicam noções sociológicas, como por exemplo, percepção do velho e do novo, da tradição e da modernidade. Estas nos auxiliam a refletir sobre o problema de pesquisa, da formação de culturas identitárias na contemporaneidade, das novas e velhas relações estabelecidas nos grandes centros urbanos, como é o caso da cidade de São Paulo, tendo a alimentação como coadjuvante da formação de identidades coletivas.

Percebemos, em um primeiro momento, o conceito de identidade como uma construção relacional, um lugar no mundo para determinados grupos, com relações de tensões e de contato. Um momento histórico e social que admitimos ser de globalização - um modo como as relações globais repõem o problema das diferenças, com sentimento do mundo moderno de supressão física da distância e do tempo, de como lidamos com as relações entre humanos e coisas, os não humanos. ${ }^{5}$ Recorremos, também, aos estudos antropológicos que sempre trabalharam com a distância cultural e com as relações interpessoais. 
Podemos refletir, diante da problemática levantada, segundo Elias, ${ }^{3}$ sobre a maneira como pensamos nosso conhecimento das relações entre pessoas isoladas, e como pensamos "as relações entre objetos não humanos e suas modificações, a relação de causa e efeito, por exemplo”. As duas formas de pensar, segundo o autor, estão ligadas a uma forma "peculiar de autoconsciência [...]. No entanto, essas formas de pensamento são vistas, no mais das vezes como algo natural e "universalmente humano, como a forma de autoconsciência humana, a imagem que as pessoas têm de si em todas as épocas". 3

Podemos refletir como esse tipo de pensamento permanece na sociedade, na medida em que inspira segurança e, de forma diferente, como algo fora do homem, - ou seja, que não é natural, e sim construído - traz desconforto, pelo sentimento de incerteza, de insegurança. Essa perspectiva interfere na formação da identidade dos indivíduos que a formulam segundo suas crenças, suas relações e perspectivas aos quais estão inseridos em conjunto, numa sociedade. A partir de uma aprendizagem social, o indivíduo torna-se cada vez mais consciente do seu "eu", desenvolvendo um "ego" do indivíduo que não lhe é natural, mas aprendido em sociedade.

Outro ponto a ser tratado neste artigo é a construção da nação brasileira a partir de alimentos e comidas classificadas como nacionais, regionais e locais, representativas da cultura brasileira. Trabalhamos tal ideia a partir da teoria de Tradições Inventadas, de Eric Hobsbawm, ${ }^{6}$ que afirma:

Por tradição inventada entende-se um conjunto de práticas, normalmente reguladas por regras tácitas ou abertamente aceitas, tais práticas de natureza ritual ou simbólica, visam inculcar certos valores e normas de comportamento através da repetição, o que implica, automaticamente, uma continuidade em relação ao passado. Aliás, sempre que possível, tenta-se estabelecer continuidade com um passado histórico apropriado. (p. 9).

Desse modo, torna-se possível pensar o Mercado Municipal Paulista como um ícone de São Paulo, ponto turístico demarcado pela tradição, que representa a diversidade da cidade, uma vez que há comerciantes de diferentes etnias, que vendem produtos genuínos de suas terras, que em certa medida ajudaram a compor o paladar e o prato do paulistano. Trata-se de uma tradição inventada em amplo sentido.

Diante desse emaranhado de situações e contextos, refletiremos sobre as construções identitárias do paulistano, bem como a construção da nação brasileira, tendo como pano de fundo o contexto da alimentação que sustenta as relações vivenciadas no ambiente do Mercado Municipal de São Paulo. 


\section{0 mercado municipal de São Paulo: da alimentação à comida do paulistano - uma construção identitária da cidade}

O mercado municipal de São Paulo, ou Mercadão, como ficou popularmente conhecido, começou a ser construído em 1928, sendo finalizado em 1932, quando ocorreu a Revolução Constitucionalista de 1932 em São Paulo." Foi então usado como armazém para armamentos do exército. ${ }^{7}$ Foi inaugurado no ano de 1933, com uma construção neoclássica de $22.230 \mathrm{~m}^{2}$ delimitada entre as ruas da Cantareira, Mercúrio, Assad Abada e Avenida do Estado, no centro de São Paulo. Possui bela arquitetura e belos vitrais do artista russo Conrado Sorgenicht Filho, em lugar do Mercado Central, situado na Rua 25 de Março, com comércio de produtos alimentícios ao ar livre.

Seu espaço é organizado entre diferentes comércios: por exemplo, de cereais, legumes, frutas e flores, ocupando 40\% do espaço; 20\% para laticínios e salgados; $10 \%$ para carnes verdes; $10 \%$ para peixes e $20 \%$ para aves e outros tipos de carnes. ${ }^{8}$ Desde sua inauguração, o Mercado funciona com pontos hereditários no sistema de permissão, que segundo Desgualdo Netto, " "seria a locação do espaço a título precário, em que o locatário se sujeita às posturas legais específicas podendo cessar unilateralmente, sem que envolva pendências ou ônus para qualquer parte". Dessa maneira, a maioria de bancas ou boxes é composta por familiares que ocupam os espaços há gerações, desde a inauguração, passando de pai para filho e, atualmente, para neto, estando em sua terceira geração.

Suas características eram, inicialmente, de mercado distribuidor de alimentos, comercializando variados tipos alimentícios nacionais e importados. No entanto, ao final da década de 1970 seu comércio foi enfraquecendo, perdendo vendas para as redes de supermercado que se instalavam na cidade, trazendo facilidade ao consumidor para encontrar uma variedade de produtos em um só lugar e preços convidativos.

Essa transformação de consumo da cidade resultou em uma queda considerável nas vendas das bancas do Mercado. Segundo Kirsten (1980), apud Netto: ${ }^{9}$

[...] Os hábitos de compra [do paulistano] haviam mudado profundamente, particularmente nas compras em supermercados (16,2\% em 1971 para 40,24\% em 1980), enquanto as feiras-livres praticamente mantiveram sua participação relativa na preferência das donas de casa. Por sua vez, a participação dos mercados municipais da Capital havia reduzido de 2,5\% para 0,12\% dos gastos familiares (p. 4).

* A Revolução Constitucionalista de 1932 de São Paulo foi um movimento contra o Governo Provisório de Getúlio Vargas e a promulgação de uma nova Constituição para o Brasil. Ocorreu entre julho e outubro de 1932. Segundo Abreu,10 a "Revolução Constitucionalista de 1932 é um objeto disputado. Desde o seu fim, os vencedores procuraram representá-la como tentativa de separatismo ou como movimento contrarrevolucionário que buscava assegurar a volta ao poder das oligarquias paulistas depostas em 1930" (p. 318). Atualmente considera-se 09 de julho a marca de início do movimento, sendo instituído feriado cívico estadual. 
Essa realidade enfrentada pelo Mercado permaneceu até a década de 1990, com permissionários fechando suas bancas ou passando para outros responsáveis, por não mais conseguirem sustentar os negócios. Foi no ano de 2004 que o Mercado Municipal angariou verba da prefeitura para uma ampla reforma, que fez parte dos projetos de revitalização do centro velho da cidade. Sua fachada foi restaurada, assim como os vitrais, e foi construído um mezanino de $2.000 \mathrm{~m}^{2}$ para acomodação de novas lanchonetes no espaço, a fim de estimular o turismo no local. ${ }^{11}$

O Mercado possui, atualmente, 291 boxes distribuídos em $12.600 \mathrm{~m}^{2}$, com um público estimado de 14 mil pessoas ao dia e cerca de 1.600 funcionários. Existem ainda $1.600 \mathrm{~m}^{2}$ de subsolo, abrigando sanitários, fraldário, enfermagem e a máquina de ozônio instalada para amenizar o cheiro de esgoto e manutenção para erradicação de pragas no local. São comercializadas aproximadamente 350 toneladas de alimentos ao longo do dia, visto que só fecha suas portas das 18 horas às 20 horas. ${ }^{7}$

É um espaço grandioso, com atividades não somente relacionadas ao trabalho, mas outros modos de interação social, que serão abordados em momento oportuno neste trabalho. Primeiramente, devemos realizar uma análise geral do contexto para que possamos apreender as relações estabelecidas nesse espaço.

O mercado abriga diferentes tipos de mercadorias, a maioria voltada aos produtos alimentícios, e após a revitalização em 2004, um espaço para novas tendências de mercados se abriu e novos produtos e artefatos passaram a ser comercializados, havendo uma justaposição entre o "velho e o novo". Nesse sentido, podemos observar que tradição e modernidade ora se misturam, ora se opõem, coexistindo nesse ambiente.

Para melhor compreendê-lo, o classificamos em três diferentes práticas comerciais, atribuindolhe uma categoria específica conforme o que percebemos nos próprios permissionários. Podemos afirmar, assim, que o espaço do mercado está dividido entre os boxes chamados de "empórios", que comercializam queijos, embutidos, bacalhau, azeites e condimentos importados; os de frutas, peixes e carnes, que comercializam frutas nacionais e importadas de alta qualidade, peixes de água doce e de água salgada, e carnes variadas; e por último, os de gastronomia e souvenires, compostos de bares, lanchonetes, restaurantes que servem as iguarias do local e bancas com artefatos nacionais que servem como presentes e lembranças, sendo estes três grupos de comércio, categorizados, respectivamente, como o tradicional, o popular e o moderno.

O espaço do tradicional é o mais conservador do mercado, muitas vezes são bancas mais antigas, que buscam manter tradição e dão continuidade ao trabalho familiar, passando de geração em geração como forma de manter uma identidade nacional das raízes migrantes, dos costumes da terra natal, como forma de preservar o orgulho de manter um trabalho restrito à família.

A migração presente entre os permissionários é, em sua maioria, de italianos, portugueses e espanhóis, que possuem bancas no Mercado desde a inauguração e que continuam com o trabalho 
familiar. Percebemos também uma parcela de migrantes nortistas e nordestinos, que se mudou para São Paulo nas décadas de 1960 e 1970 em busca de oportunidades de trabalho; muitos se estabeleceram no comércio do Mercado, primeiramente como funcionários e, posteriormente como permissionários.

O espaço popular é onde os costumes brasileiros de feiras-livres são praticados de modo semelhante dentro do Mercado, mais comuns nas bancas de frutas, peixes e carnes, de modo que seus funcionários abordam os clientes chamando-lhes a atenção com brincadeiras, apelidando-os e fazendo chacotas entre si. Exemplo disso são as piadas feitas entre os funcionários, que as criam para se divertir e tornar a jornada de trabalho menos dura. Por exemplo, uma brincadeira comum entre eles é buscar nos clientes semelhanças físicas e de aparência com os colegas de trabalho e, por conseguinte, chamá-los pelo nome do colega a que eles atribuem a semelhança; assim, apelidam os clientes, abordam-nos oferecendo degustação de frutas, afirmando ter o melhor preço e qualidade em seus produtos. Frases de praxe ouvidas em feiras-livres também são comuns nas ruas em que se agrupam as bancas de frutas, como "mulher bonita não paga, mas também não leva".

O espaço que chamamos de "moderno" é composto por dois tipos de comércio no Mercado - o gastronômico e o de souvenires e produtos nacionais - sendo mais utilizado entre os turistas que buscam as iguarias classificadas como tradicionais do mercado, como o sanduíche de mortadela e o pastel de bacalhau; ou ainda a loja que comercializa produtos para presentes, como canecas do Mercado, com símbolo de São Paulo e do Brasil, canetas, camisetas, copos, chaveiros, chinelos, bonés; e ainda o box que trabalha com produtos artesanais, como bijuterias e joias com pedras nacionais, bolsas, roupas, chinelos, etc.

Esse espaço é o campo mais jovem formado no Mercado, fruto da reforma e dos novos interesses da administração do local em torná-lo um chamariz para o público que visita São Paulo para compras nos comércios populares no entorno da Rua 25 de Março, que recebem turistas de todos os estados brasileiros. Dentro dessa nova perspectiva para o mercado, foram abertos espaços para outros tipos de produtos antes pouco procurados e/ou comercializados, como condimentos e produtos exóticos brasileiros, produtos árabes e asiáticos, etc.

Um comportamento percebido nesses três espaços seria a relação entre funcionários e clientes. No espaço tradicional (dos empórios), o trato entre funcionários e clientes é mais formal e de cordialidade, no sentido de haver mais intimidade quando se trata de clientes antigos que fazem suas compras há anos no mesmo local, permitindo ao funcionário saber suas preferências, gostos e tipos de produtos que procuram. Já no espaço popular (principalmente de frutas e peixes), a relação entre funcionários e clientes é mais descontraída, informal, com as brincadeiras e tipos de abordagem comuns às feiras-livres. E, por fim, no espaço moderno (de souvenires e de gastronomia), a relação estabelecida é de agradar ao turista, informá-los dos costumes locais, tratá-los como clientes especiais que buscam informações e histórias do local. 
Assim, turistas e clientes são classificados de modo diferente entre os funcionários, havendo até mesmo momentos de hostilidade, uma vez que os turistas, na maioria das vezes, são considerados clientes apenas pelo espaço do moderno e não pelos demais. Alguns funcionários das bancas de frutas, por exemplo, chamam os turistas de moscas que visitam o mercado, olham as mercadorias, mas nada compram, segundo declarações de alguns deles.

Nesse sentido, há uma rivalidade entre os permissionários mais antigos que ocupam os boxes de empórios, de frutas, de carnes e demais produtos alimentícios com as bancas que oferecem alimentação rápida, sobretudo os restaurantes localizados no mezanino - símbolo da modernidade e da nova função atribuída ao mercado quando se propôs a reforma como parte do projeto de revitalização do Centro Velho da cidade, tornando-o um ponto turístico de São Paulo.

Essa rivalidade se mostra evidente nas primeiras conversas entre os permissionários mais antigos, que recebem, em defesa, a hostilidade dos permissionários mais jovens. Segundo um antigo cliente, Gino Venneri,** até 2004 era um mercado distribuidor de alimentos, quase não havia boxes de lanchonetes.

Leonardo Chiappetta*** administra uma das bancas mais antigas, iniciada por seu avô quando da inauguração do Mercado, passou para seu pai e hoje é de responsabilidade dele e do irmão. Ele tenta manter a tradição de seu empório, sua história no comércio e, por conseguinte sua história familiar, iniciada com a migração italiana ao Brasil no começo do século XX e consolidada no comércio. Sua família atua no ramo de importação de embutidos, bacalhau, azeites e outros alimentos desde 1908, tendo se estabelecido no Mercado Municipal em 1933. Leonardo defende a tradição e as origens do Mercado, afirmando que ele não é só sanduíche de mortadela, que "há muito mais coisas por trás e, que essa nova fama pode descaracterizar o local”. A mesma opinião é compartilhada pelas pessoas mais antigas instaladas no mercado, os primeiros imigrantes que conseguiram permissão para ocupar um box e comercializar seus produtos.

Por outro lado, temos a opinião dos mais jovens no mercado, sobretudo aqueles que iniciaram suas atividades entre o final da década de 1990 e início dos anos 2000. Para essas pessoas, o Mercado precisava modificar sua administração, reestruturar-se e sobreviver às novas tendências do mercado brasileiro, principalmente com a cultura de super e hipermercados presentes nas cidades, com grandes redes de comércio, em que há uma variedade de produtos, marcas e preços,

** Gino Venneri é cliente, italiano, que trabalhou no Ceasa, e distribuía no Mercadão, hoje é aposentado. Frequenta o mercado todos os dias pela manhã. É italiano, está no Brasil desde 1950, veio com 22 anos. De 1950 a 2002 , segundo ele, vendia para todos os peixeiros do mercado. Entrevista realizada no dia 08 de janeiro de 2013.

*** A entrevista com Leonardo Chiappetta foi realizada no dia 09 de janeiro de 2013, com apresentação de seus dois boxes, o empório e a sorveteria, que é cuidada por sua mãe. Leonardo é engenheiro, mas deixou de exercer a profissão desde 2008 para assumir a administração do empório, que hoje tem loja também fora do mercado, em um shopping da cidade. 
havendo a necessidade real de buscar novas formas de condutas para levantar a procura pelos produtos comercializados no mercado, assim como alavancar seus lucros e conseguir manter-se aberto perante a economia da época.

Para Hugo, permissionário do box Mercapoint, após a reforma de 2004, o Mercado sofreu transformações consideráveis, passando a fazer parte do percurso turístico da cidade. Dessa forma, o que era um mercado de abastecimento alimentício passou a ser um mercado "cultural, histórico e gastronômico"***** Há uma dificuldade de aceitação por parte dos mais antigos:

Que são todos trabalhadores, honestos que trabalham demais, são muito simplórios, por isso, talvez a ignorância de aceitar o novo, por não saberem o que podem e o que não podem fazer aqui. Eles compram e vendem, tudo de uma maneira bem simples, passado de pai para filho, com os mesmos costumes da década de 50, assim, não aceitam mesmo as pessoas que vêm com essa cabeça de mudar o Mercado, de se beneficiar desse fluxo de turistas e aumentar suas vendas, para eles, tem que continuar como era antigamente, o fulano vem comprar um quilo de arroz, o outro vem buscar feijão, o dono do bar busca os embutidos, não sabem lidar com o varejo de hoje. (Hugo, 2012).

Encontramos, assim, duas principais perspectivas de compreender o Mercado Municipal entre a ideia do novo e a ideia do velho: um que possui uma ideia atual, com base na administração do mercado e de suas novas tendências; e o outro, com uma ideia saudosista que deseja preservar os antigos costumes e continuar no mesmo modo de atuação dentro do mercado, sem necessidade de atualizar suas estratégias de vendas e táticas mercadológicas.

Além dessas situações que envolvem diretamente as relações de trabalho, existem outras formas de relações sociais que ocorrem entre as ruas do Mercado Municipal, como os graus de parentescos entre os funcionários, onde trabalham maridos e esposas, pais, filhos, netos, tios e sobrinhos, além de vínculos familiares adquiridos por rituais simbólicos, como por exemplo, batismos dos filhos desses funcionários e permissionários.

Outras relações ainda são adquiridas por meio de entretenimento e lazer presentes no mercado, como os jogos lotéricos, legalizados no Brasil; jogos de "bolões”, em que funcionários se reúnem para apostar determinados valores nos jogos acumulados. Além desse tipo de jogo, muito frequentes no local são as apostas de jogo do bicho, um jogo ilegal no Brasil, mas que ocorrem diariamente e movimentam as bancas, uma vez que eles apostam entre si e buscam informações sobre o que o permissionário vizinho jogou.

**** Entrevista realizada no dia 10 de janeiro de 2012 no box 42/44 - Mercapoint, situado na rua M. do Mercado Municipal de São Paulo. Hugo é o proprietário do box que está em funcionamento desde 2010. 
A partir dessa situação, em que encontramos diversos elementos a serem estudados e analisados em suas formas lógicas e simbólicas de lidar com o cotidiano do Mercado Municipal, que fecha apenas duas horas por dia, podemos discutir como São Paulo passa por essas relações em que podemos refletir sobre sua identidade e suas formas de alimentação. Analisamos, assim, as relações de identidade local, regional, nacional e global que são compreendidas segundo os alimentos que são comercializados no local.

Temos as referências da já mencionada comida de dentro, que seriam os produtos classificados como locais - o lanche de mortadela, o bolinho e o pastel de bacalhau e as saladas de frutas -, comercializados pela maioria dos bares e lanchonetes, por serem muito procurados. Há também as comidas de boteco, com referência a uma tradição alimentar de Minas Gerais, quitutes e iguarias apreciadas em bares para alavancar o turismo gastronômico na região. E há também as bancas que comercializam produtos regionais, como farinha de mandioca produzida em diferentes estados, queijos frescos, temperos, tapioca, azeite de dendê e outros produtos regionais do Brasil.

A comida nacional é representada sobretudo por meio de um prato reconhecidamente nacional, a feijoada, com bancas que comercializam produtos para seu preparo. Por exemplo, há a banca do senhor Quintas, presente no mercado desde a inauguração, com a venda de cortes de carne suína, diferentes tipos de feijões, linguiças, paios e outros produtos necessários para o preparo do prato.

O Mercadão tenta, em seu marketing de divulgação, reforçar a ideia de identidade global da cidade de São Paulo, recorrendo ao título de São Paulo como a capital do mundo e de cidade cosmopolita que abriga cidadãos de todo o mundo. Parte de seus consumidores são habitantes da cidade de São Paulo advindos de outras localidades e que buscam preservar suas tradições, costumes e sua alimentação. Assim, a justificativa é que ali são comercializados produtos importantes, provenientes de diferentes países, bacalhau da Noruega, azeite, azeitonas, embutidos espanhóis, massas e molhos italianos, produtos árabes, asiáticos, frutas e especiarias do mundo todo, buscando retratar essa tendência global presente no país, especialmente na capital paulista. Os boxes que trabalham com produtos importados atendem seus fregueses imigrantes e brasileiros que querem conhecer e apreciar alimentos provenientes de outras culturas.

O Mercado Municipal de São Paulo traz consigo essas relações identitárias da alimentação do paulistano, desde sua formação, com produtos regionais, das farinhas ao arroz e feijão e carne seca, aos aspectos da influência da migração, com massas, molhos de tomates e ervas, diferentes tipos de peixes e frutos do mar, até a internacionalização das cozinhas, com produtos dos mais exóticos e variados possíveis. 


\section{Tradição e nação: comida como elemento de construção do Brasil - 0 mercadáo como representante da história da alimentação brasileira e seus hábitos culturais}

Mediante as relações intersociais que envolvem o comércio de produtos nacionais e importados no Mercado Municipal, podemos tratar suas iguarias na perspectiva deHobsbawm, ${ }^{6}$ de tradição inventada, em amplo sentido.

Percebemos o Mercado como um espaço que apresenta a diversidade cultural e a tradição alimentar de São Paulo como uma ideia de tradição inventada, uma vez que o Mercado e seu comércio datam de 1933 - historicamente não de longa data, se considerarmos a idade de formação da cidade. Também podemos considerar o fato de que alguns dos permissionários passaram a comercializar alimentos e condimentos étnicos no mercado após sua inauguração, alguns na década de 1960 e outros tantos já na década de 1990.

Nesse sentido, de tradição inventada, devemos considerar o período após a reforma de 2004, que se mostrou um divisor de águas para a história do mercado como uma reformulação, ganhando caráter de ponto turístico, primeiro pela beleza e originalidade arquitetônica preservada; segundo por sua permanência e importância do comércio popular; e em terceiro, pelos produtos e histórias construídos ao longo dos anos.

A partir desse projeto de reestruturação que abrigou diversos restaurantes, bares e lanchonetes, buscou-se resgatar relatos de histórias do vividas no mercado e elementos que identificassem o local, inventando o lanche gigante de mortadela como símbolo do local, uma iguaria de tradição do mercado, classificando a comida local, de dentro, que faz parte de uma identidade do Mercado.

Contudo, na medida em que há referência a um passado histórico, as tradições inventadas caracterizam-se por estabelecer com ele uma continuidade bastante artificial. Em poucas palavras, elas são reações a situações novas que ou assumem a forma de referência a situações anteriores, ou estabelecem seu próprio passado através da repetição quase obrigatória. ${ }^{6}(p .10)$.

Assim foi criado o lanche de mortadela como produto tradicional do mercado. A junção da história do seu Manuel, por exemplo, primeiro permissionário do Bar do Mané, pai de Marcos (atual permissionário do box), com a popularidade do sanduíche de mortadela nos anos iniciais do Mercado, por ser de preço mais acessível e apreciado no Sudeste, criou uma tradição do lanche, recriando seu significado frente aos turistas que visitam, muitas vezes, exclusivamente o bar, pelas suas histórias, e comer o lanche "original” com trezentos gramas de mortadela.

Em uma das visitas ao Mercado, tal tradição pôde ser observada e concretizada, com um turista proveniente de Fortaleza, que pediu um sanduíche de mortadela, um refrigerante e uma foto com 
Marcos de avental e boné do bar, para mostrar, segundo ele, "aos amigos que realmente comeu o lanche original e não de bares genéricos do mezanino”.

Isso reforça como, a partir da proposta artificial de um lanche criado para ser um atrativo turístico como produto divulgador do Mercado Municipal, tem-se em sua reprodução em diferentes lanchonetes a venda de muitos lanches ao dia, tornando a tradição inventada uma realidade. Isso traz disputas pela veracidade de fatos e originalidade, como o caso do Bar do Mané, que afirma ser o criador do lanche de mortadela produzido com trezentos gramas do embutido, inventado a partir de uma antiga história do primeiro dono do Bar, o seu Mané, que caprichava na montagem do lanche para os carregadores de caixas que distribuíam mercadorias no local. E o Hoca Bar, em cuja divulgação consta tratar-se do bar tradicional do lanche de mortadela, com a melhor marca do embutido, garantindo a qualidade do lanche.

A partir desses discursos de histórias e do uso de determinadas marcas de produtos utilizados na confecção dos lanches, busca-se uma autenticidade nas históricas contadas, na tentativa de maiores vendas e lucratividade.

Além desses dois bares, que estão há mais tempo no mercado, outras lanchonetes fazem o sanduíche, não reivindicando para si o posto de fazer o lanche original e verdadeiro, não no sentido de terem sido as primeiras a fazer, mas apelando para a tradição e qualidade da marca da mortadela utilizada.

Segundo Hobsbawm, ${ }^{6}$ "[h] ouve adaptação quando foi necessário conservar velhos costumes em condições novas ou usar velhos modelos para novos fins”. Isso de fato ocorreu no Mercadão após a reforma, quando se buscou conhecer diferentes narrativas para encontrar algo de original do local, chegando ao lanche de mortadela, popular e característico de um comércio popular.

A tradição, porque tradição é uma coisa antiga, né? Mas não é imutável, pra você vêe o lanche de mortadela com 300 gramas não pode ser tradicional porque isso não existia, isso é uma invenção, uma tradição adaptada, comer pão com mortadela é coisa de carregador italiano de caminhão antigo, só que ele comia duas fatias não comia meio quilo, você tem uma adaptação, então você mexeu na tradição, é mesma coisa se eu disser que a tradição é tocar samba, ai vem o Marcelo D2 e faz hip hop samba, mas ai não é mais tradição, porque foi mudado, ai você tem que ver o que significa a palavra tradição, mas é tradição brasileira fazer samba, mesmo que for misturado com hip hop $p^{* * * * *}$.

A opinião do entrevistado ilustra o que afirmamos ser tradição inventada, mas sem colocarmos em sentido subjugado ou pormenorizado; pelo contrário, exatamente a ideia de que tradição não

\footnotetext{
***** Entrevista com Hugo (realizada em 10 de janeiro de 2013), permissionário desde 2010 (box Mercapoint) mas com uma trajetória desde a infância no mercado, já que sua família é dona de box de pescados.
} 
é algo imutável, mas de ser transformada de acordo com a realidade, o significado e o uso dados a essa tradição, respeitando sua origem, mas lhe atribuindo um novo significado de ser, estar e funcionar como modo de relações socioculturais. Dessa forma, podemos perceber que, apesar de haver uma disputa por legitimidade na comercialização de certos produtos, sobretudo alimentos para serem consumidos no local, como o sanduíche de mortadela e o pastel de bacalhau, até o suco natural e a sala de frutas, há uma renovação de interesses que passa por essa nova organização que o local sofreu com as políticas públicas do governo do período de 2004 na cidade de São Paulo.

A demarcação de espaços, como velho e novo - boxes de frutas, peixes, carnes e empórios de um lado; e lanchonetes, bares, lojas de souvenires e acessórios, de outro - indicam um movimento de conflito existente em qualquer local em que haja transformações e que sigam tendências de mercado atual.

Sempre né, é que o velho e o novo também são clássicos, isso é eterno, só que foi, vamos dizer assim, foi demarcado, mas o velho e o novo sempre vão brigar, só que existe um divisor de águas aqui, como a tecnologia, a informática, né? O computador é um degrau entre o velho e o novo, né? Então essa reforma seria isso, um degrau entre o velho e o novo também, e mais ou menos isso $0^{* * * * * * *}$.

Isso afirma nossas ideias centrais de invenção e tradição em um mesmo espaço de coexistência, seguindo uma tendência mercadológica e urbanística do centro velho da cidade de São Paulo, com a preocupação de recuperar a identidade local e compreender as formas de relações locais, regionais, nacionais e internacionais da cidade.

O Mercado Municipal, hoje, segue a tendência de mercados internacionais, que segundo coleta de dados, passam por tais confrontos, mas sempre vão em direção do novo, da mistura de elementos e produtos alimentícios.

Já na Idade Média, segundo Montanari, ${ }^{12}$ "o mercado de Bolonha ou de Milão faz falar de si não tanto porque ali se encontrem alimentos locais, mas por sua capacidade de se definir como lugar de troca interterritorial, inter-regional, internacional" (p. 137). O mercado de Paris durante séculos se organizou do mesmo modo e viveu sob a mesma imagem.

O mesmo ocorre no Mercado Municipal de São Paulo, quando encontramos uma variedade de produtos regionais, nacionais e internacionais a serem comercializados, como as biojoias produzidas a partir do capim dourado, ou ainda as frutas exóticas da Amazônia, como cupuaçu e açaí, ou mesmo os produtos importados, como azeites, embutidos, massas, temperos e condimentos importados diretamente pelos permissionários de empórios e demais frutas provenientes de diferentes partes do mundo.

****** Entrevista com Hugo, do boxe Mercapoint, realizada em 10 de janeiro de 2013. 
Rubem Oliven, ${ }^{13}$ nos estudos sobre nação, demonstra de que maneira é possível compreender a construção da identidade nacional brasileira, a partir de dois movimentos que ocorreram na década de 1920 no país. Um foi em São Paulo, com representatividade nacional, em defesa da cultura brasileira e enaltecimento de artistas nacionais, com a Semana da Arte Moderna de 1922; o paulistano classifica-se e cria uma identidade nacional para então tornar-se global. A partir dessa concepção, podemos relacionar a simbologia que determinados alimentos têm no Mercadão, quando se preservam costumes e evidencia a tradição de determinados alimentos nacionais, como a farinhas de mandioca artesanais que são valorizadas nesse comércio, ou ainda as cachaças artesanais de diferentes engenhos do Brasil, ou o comércio da carne seca e outros produtos que secos para o preparo de pratos típicos.

Ainda, outro movimento de cunho regional se deu em 1926, com o Manifesto Regionalista de Gilberto Freire, defendendo uma identidade regional para então haver uma identidade nacional brasileira, com enaltecimento de costumes, festas, músicas regional. E a cozinha regional nordestina, que segundo Freire (apud Oliven ${ }^{13}$ ) deveria ser preservada, uma vez que se encontrava em crise suprimida pelos doces de lata e outros produtos em conservas e que "uma cozinha em crise significa uma civilização em perigo: o perigo de descaracterizar-se” (Freire 1976: 72 apud Oliven ${ }^{132002:}$ 28).

Dessa maneira, podemos pensar que o Mercado possui a preocupação em preservar costumes locais, regionais e nacional, com a comercialização de produtos de pequenos produtores, especiarias locais, produtos artesanais que valorizam a cultura brasileira, sem, no entanto, deixar de caminhas com as tendências da globalização, de produtos de outras nacionalidades ou ainda as lanchonetes fast food.

\section{Considerações finais}

A partir da temática abordada ao longo do texto, realizamos algumas considerações acerca das relações socioculturais ocorridas no espaço do Mercado Municipal de São Paulo, que indicam certas tendências alimentares no comércio popular do município.

As observações no Mercadão trouxeram à luz alguns elementos para debatermos sobre o conceito de figuração e de identidade-eu e de identidade-nós de Norbert Elias, ${ }^{3}$ além do conceito de tradição inventada de Eric Hosbsbawm, ${ }^{6}$ de maneira complementar uns aos outros. Observa-se que o conceito de configuração de Elias $^{2}$ trata da sociedade e sua cultura da maneira como ela está estruturada, mas que não é estanque; ela se modifica, uma realidade existente que, de um lado, impõe limites ao indivíduo, e de outro, oferece alternativas diferentes para que o indivíduo viva em seu meio. 
Nesse sentido, podemos pensar na construção de identidade-eu e na identidade-nós como um processo de aprendizado do indivíduo pela sociedade na qual se constroem costumes, hábitos que vão se consolidando ao longo de sua repetição, transformando-se em uma tradição que, ao longo do processo civilizador, de acordo com suas necessidades, realidades e tendências, toma diferentes funcionalidade e significados, podendo tornar-se uma tradição adaptada aos dias atuais - ou ainda, uma tradição inventada, com novo sentido e novas funções na sociedade a qual está inserida.

O comércio de produtos e alimentos no mercado identifica de modo fácil essas relações de identidade e formação de tradições locais, regionais, nacionais e globais com o comércio do sanduíche de mortadela, uma tradição inventada do local, aos produtos regionais, como o azeite de dendê, as frutas e os sucos de frutas da Amazônia, aos produtos nacionais, farinhas, tapiocas, cachaças, condimentos para a feijoada etc.; e os produtos globais, como temperos orientais, asiáticos, produtos típicos de diferentes países e de diferentes culturas.

O Mercado Municipal representa em si algumas práticas da sociedade paulistana que marcam diferentes extratos sociais, diferentes nacionalidades, migrações e outras relações socioculturais. Dentro do mercado, por exemplo, há um fluxo de milhares de pessoas todos os dias, dentre as quais mendigos, pedintes, comerciantes, migrantes, estrangeiros, turistas, "bicheiros", trabalhadores, seguranças, que utilizam os espaços do mercado, além dos boxes de comércio, e outros locais comuns, como a lotérica, a praça de alimentação, os caixas eletrônicos.

Podemos afirmar, dessa maneira, que existem diferentes espaços dentro do que chamamos de "Mercado Municipal Paulistano", estando presentes o lado saudosista, o lado novo, o lado velho, com conflitos, coexistências e trocas de experiências e valores.

\section{Referências}

1. Lévi-Strauss C. Introdução à obra de Marcel Mauss. In: Mauss M. Sociologia e antropologia. São Paulo: Cosac Naify; 2003.

2. Elias N. O processo civilizador. Rio de Janeiro: Zahar;1994.

3. Elias N. A sociedade dos indivíduos. Rio de Janeiro: Jorge Zahar; 1994.

4. Augé M. Não lugares: introdução a uma antropologia da supermodernidade. $8^{a}$ ed. Campinas: Papirus; 2010.

5. Latour B. Jamais fomos modernos. Rio de Janeiro: Editora 34; 1993.

6. Hobsbawm E, Ranger T. A invenção das tradições. Rio de Janeiro: Paz e Terra; 1997.

7. Soares CJ. Mercados do Brasil: de norte a sul. Belo Horizonte: Autêntica; 2009.

8. Alves AC. Mercado Municipal de São Paulo: 70 anos de cultura e sabor. São Paulo: Intermédica; 2004. 
9. Desgualdo Netto D, Tsunechiro A, Barros LOS, Amaro AA. Abastecimentos de centros urbanos do estado de São Paulo: mercados municipais. São Paulo: Governo do Estado de São Paulo, Instituto de Economia Agrícola; 1987. 33 p. Relatório de Pesquisa, 03/87. [acesso em: 19 set. 2013]. Disponível em: ftp://ftp.sp.gov.br/ftpiea/RP/1987/relat-0387.pdf.

10. Abreu MS. As comemorações da Revolução Constitucionalista de 1932: representação do passado e construção social do espaço regional (São Paulo, 1934 e 1955). Estudos Históricos [Internet] 2007; (40):153-171. [acesso em: 18 dez. 2013]. Disponível em: http://bibliotecadigital.fgv.br/ojs/index.php/ reh/article/view/1290/433

11. Tiradentes JA. Mercado municipal paulistano: 75 anos de aromas, cores e sabores. São Paulo: Supra; 2008.

12. Montanari M. Comida como cultura. São Paulo: Senac São Paulo; 2003.

13. Oliven RG. Cultura brasileira e identidade nacional (o eterno retorno). In: Miceli S. O que ler na ciência social brasileira. São Paulo: Anpocs; 2002.

Recebido: 04/3/2015

Revisado: 05/6/2015

Aprovado: 08/7/2015 
